\title{
Noninvasive pressure preset ventilation for the treatment of Cheyne-Stokes respiration during sleep
}

\author{
G.N. Willson*, , I. Wilcox"ף, A.J. Piper*, W.E. Flynn*, M. Norman*, , R.R. Grunstein*, \\ C.E. Sullivan*,
}

\begin{abstract}
Noninvasive pressure preset ventilation for the treatment of Cheyne-Stokes respiration during sleep. G.N. Willson, I. Wilcox, A.J. Piper, W.E. Flynn, M. Norman, R.R. Grunstein, C.E. Sullivan. (C)ERS Journals Ltd 2001.

ABSTRACT: Cheyne-Stokes respiration (CSR) during sleep is common in patients with congestive heart failure (CHF). This pattern of breathing fragments sleep, leading to daytime symptoms of sleepiness and fatigue. It was hypothesized that by controlling CSR with noninvasive pressure preset ventilation (NPPV), there would be a decrease in sleep fragmentation and an improvement in sleep quality.

Nine patients (eight males, one female; mean \pm SD $65 \pm 11$ yrs) with symptomatic CSR diagnosed on overnight polysomnography (apnoea/hypopnoea index (AHI)

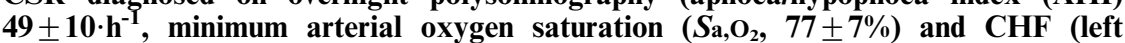
ventricular ejection fraction $25 \pm 8 \%$ ) were studied. After a period of acclimatization to NPPV (variable positive airway pressure (VPAP) II ST $^{\mathrm{TM}}$, Sydney, NSW, Australia and bilevel positive airway pressure (BiPAP) ${ }^{\mathrm{TM}}$, Murraysville, PA, USA), sleep studies were repeated on therapy.

NPPV almost completely abolished CSR in all patients with a reduction in AHI from $49 \pm 10$ to $6 \pm 5 \cdot h^{-1}(p<0.001)$. Residual respiratory events were primarily due to upper airway obstruction at sleep on-set. Arousal index was markedly decreased from $42 \pm 6$ to $17 \pm 7 \cdot h^{-1}(\mathbf{p}<\mathbf{0 . 0 0 1})$. Sleep architecture showed a trend toward improvement with a reduction in stage 1 and $2(79 \pm 7 \%$ during the diagnostic night versus $72 \pm 10 \%$ during NPPV, $(p=0.057)$, whilst sleep efficiency, slow-wave sleep (SWS), and rapid eye movement (REM) were not altered.

Controlling Cheyne-Stokes respiration with noninvasive pressure preset ventilation resulted in reduced arousal and improved sleep quality in the patients with congestive heart failure. Noninvasive pressure preset ventilation should be considered a potential therapy for Cheyne-Stokes respiration in congestive heart failure in those patients who do not respond or fail to tolerate nasal continuous positive airway pressure therapy.
\end{abstract} Eur Respir J 2001; 17: 1250-1257.

\begin{abstract}
*Centre for Respiratory Failure and Sleep Disorders, "Dept of Cardiology, Royal Prince Alfred Hospital, and David Read Laboratory, Dept of Medicine, University of Sydney, Sydney, Australia.
\end{abstract}

Correspondence: G.N. Willson, Sleep Disorders Unit, Royal Prince Alfred Hospital, Missenden Road, Camperdown NSW 2050, Australia.

Fax: 61295157196

Keywords: Cheyne-Stokes respiration congestive heart failure

intermittent positive pressure ventilation

noninvasive pressure preset ventilation sleep apnoea syndromes

Received: September 301999

Accepted after revision December 27 2000

This study was supported by a project grant from the National Health and Medical Research Council of Australia.
Cheyne-Stokes respiration (CSR) is a crescendodecrescendo pattern of breathing, which is often observed during sleep in patients with congestive heart failure (CHF) [1, 2]. Although the pathophysiology of CSR has not been completely elucidated, it is associated with an augmented ventilatory response to carbon dioxide [3, 4], awake hypocapnia and relative hyperventilation during sleep $[5,6]$. These changes, together with the alteration in apnoea threshold during the transition from wakefulness to sleep [7], are thought to be major contributing factors to this instability in breathing during sleep. CSR during sleep results in poor sleep quality, due to arousals and altered sleep architecture, repetitive oxygen desaturation and increased sympathetic nervous system activity [8]. In turn, patients with CSR may complain of daytime somnolence, fatigue and insomnia typical of other forms of sleep disordered breathing. Moreover, CSR appears to be a marker of poor prognosis in $\mathrm{CHF}[9,10]$.

There is no universally accepted treatment for CSR during sleep in patients with CHF. Proposed therapies include low flow oxygen [11], theophylline [12] and nasal continuous positive airways pressure (nCPAP) $[13,14]$. In a series of controlled studies from one centre, nCPAP was shown to decrease apnoea/ hypopnoea index (AHI) and improve daytime myocardial function in heart failure patients [14-16]. Despite these findings, a number of authors have found nCPAP to be ineffective in controlling CSR [17-19]. In the authors' experience, nCPAP controls CSR only in the minority of patients and is generally poorly tolerated in the home. The authors recently reported preliminary data showing that CSR was abolished and sleep improved with noninvasive nasal ventilation using a time cycled volume preset ventilator [20]. In that study, the prolonged use of noninvasive ventilation was also associated with an improvement in cardiac function in patients who used the device. However, despite its effectiveness, a number of patients failed to tolerate the volume preset device in domiciliary setting. Patients reported 
difficulty synchronizing their breathing with the volume preset device, due to the mandatory nature of the set respiratory rate and the insensitivity of the inspiratory triggering. Noninvasive pressure preset ventilation (NPPV) is now widely used in patients with nocturnal respiratory failure, and this modality is generally more comfortable than volume preset ventilation $[21,22]$.

The effectiveness of pressure preset ventilation has not previously been examined in CSR. This mode of treatment may be as effective as volume preset ventilation in reducing CSR during sleep and thus potentially be a better tolerated therapy. Alternatively, when a patient with CSR is permitted to trigger a pressure preset ventilator, it is possible that this would aggravate the underlying breathing control instability and cause even greater hyperventilation during sleep. The purpose of this study was to determine if pressure preset ventilation could be used to control disordered breathing during sleep, thus decreasing respiratory events and arousals.

\section{Methods}

\section{Patient selection}

Patients with moderate-to-severe stable chronic left ventricular heart failure, documented severe repetitive central sleep apnoea $\left(>30 \cdot \mathrm{h}^{-1}\right)$ and minimal obstructive apnoea ( $<10 \%$ of respiratory events), were eligible for inclusion in the study. Patients were excluded if they had been admitted to hospital or changed their medication within 1 month of the study, or if there was a history of significant pulmonary disease. All patients consented to participate in the study and the protocol was approved by the Ethics Committee of the study institution.

All patients were examined by a cardiologist to confirm both historical and clinical evidence of $\mathrm{CHF}$. Subjects underwent measurements of anthropometric variables (height/weight), awake arterial blood gases and left ventricular ejection fraction (LVEF) using radionuclide gated blood pool scanning with technetium 99 pertechnetate.

Patients underwent two sleep studies, a diagnostic study whilst breathing room air (Dx) and, following a period of acclimatization, a study whilst receiving NPPV using room air. All subjects continued to take their normal cardiac medications throughout the period of the study.

\section{Sleep studies}

All patients had overnight full sleep studies between 21:00 - 07:30 h. Sleep state was monitored using two channels of electroencephalogram (C4/A1,01/A2 or C3/A2,02/A1), two channels of electro-oculogram (EOG: LOC/ROC), and one channel of submental electromyogram (EMGs). Breathing variables which were monitored included chest wall and abdominal motion (Respitrace ${ }^{\mathrm{TM}}$, Ambulatory Monitoring Inc., Ardsley, NY, USA), diaphragm electromyogram
(EMGd), arterial oxyhaemoglobin saturation $\left(\mathrm{Sa}_{\mathrm{a}} \mathrm{O}_{2}\right.$ : Biox3700e; Ohmeda, Boulder, CO, USA), and nasal airflow using a pressure transducer (Grass Volumetric; Grass Instruments, Quincey, MA, USA) or flow sensor (AutoSet ${ }^{\mathrm{TM}}$, ResMed Inc., Sydney, Australia). Electrocardiograms were measured continuously in all patients. All variables were recorded on a 16 channel polygraph (Model 78; Grass Instruments, Quincey, MA, USA or Sleepwatch ${ }^{\mathrm{TM}}$ Compumedics, Melbourne, Australia). Transcutaneous carbon dioxide $\left(T_{\mathrm{c}, \mathrm{CO}_{2}}\right.$; Tina, Radiometer, Copenhagen, Denmark) was also measured and recorded with $\mathrm{Sa}_{\mathrm{a}} \mathrm{O}_{2}$ to a personal computer based data acquisition system (analogue-to-digital (A/D) board National instrument AT-MIO-16, sampling at $10 \mathrm{~Hz}$ ).

Sleep state was scored in 30 -s epochs according to standard criteria [23]. To facilitate analysis, sleep stages 1 and 2 were combined, as were stages 3 and 4 (slow-wave sleep (SWS)). Sleep stages were expressed as a percentage of total sleep time (TST). Sleep efficiency was defined as the percentage of the total recording time that was scored as sleep. Arousal was defined as an awakening for $>3 \mathrm{~s}$ [24].

Apnoeas were defined as a cessation of airflow for $\geqslant 10 \mathrm{~s}$. Hypopnoeas were classified as a $\geqslant 50 \%$ decrease in airflow or thoraco-abdominal motion for $\geqslant 10 \mathrm{~s}$ with $\mathrm{a} \geqslant 3 \%$ decrease in oxygen saturation. Apnoeas were defined as central if airflow cessation was associated with an absence of diaphragm EMG and thoraco-abdominal wall movement. The number of events per hour of sleep was calculated and expressed as the AHI. Respiratory events whilst receiving NPPV were scored in the presence of desaturation $(>3 \%)$ and arousal preceded by a period of reduced thoraco-abdominal wall motion. The minimum average $\mathrm{Sa}_{\mathrm{a}} \mathrm{O}_{2}$ was calculated as the mean of the minimum value for $\mathrm{Sa}_{\mathrm{a}} \mathrm{O}_{2}$ in each 30 -s epoch. The minimum $\mathrm{Sa}_{\mathrm{a}} \mathrm{O}_{2}$ was the lowest value recorded during sleep. The change in $T_{\mathrm{c}}, \mathrm{CO}_{2}$ whilst receiving NPPV was analysed. $T_{\mathrm{c}}, \mathrm{CO}_{2}$ awake was the baseline value recorded $\geqslant 7$ mins after probe placement whilst the patient was breathing spontaneously. Due to the drift often seen in the $T \mathrm{c}, \mathrm{CO}_{2}$ trace, $T \mathrm{c}, \mathrm{CO}_{2}$ asleep was calculated as the mean of the first $30 \mathrm{~min}$ (measured in intervals of $1 \mathrm{~min}$ ) of stable nonrapid eye movement (NREM) sleep. The recording of $T \mathrm{c}, \mathrm{CO}_{2}$ was unsuccessful in three patients due to the presence of artifact (two patients) and malfunction of the recording device (one patient). Data from a subsequent study using NPPV was used for analysis in these patients. Heart rate was calculated by hand as the mean of the first $30 \mathrm{~min}$ of stable NREM sleep during both Dx and NPPV.

\section{Initiation of noninvasive pressure preset ventilation}

A pressure preset ventilator (either VPAP II ST ${ }^{\mathrm{TM}}$, ResMed Inc., Sydney, Australia and bilevel positive airway pressure (BiPAP) ST ${ }^{\mathrm{TM}}$, Respironics, Murrayville, USA depending on machine availability) was used, which allowed the setting of expiratory positive airways pressure (EPAP), inspiratory positive airways pressure (IPAP), breath rate and inspiratory time 
(\%IPAP or IPAPmax). Patients used commercially available nasal masks and head straps (Sullivan ${ }^{\mathrm{TM}}$, ResMed Inc., Sydney, Australia), and all needed a chin strap to prevent or minimize mouth leaks. Noninvasive ventilation was commenced predominantly on an inpatient basis (one patient began NPPV at home), with the patients acclimatizing to the device during daytime practice sessions and then gradually increasing the hours the machine was used at night. During the inpatient acclimatization nights patients were monitored continuously during sleep with both $\mathrm{Sa}_{\mathrm{a}} \mathrm{O}_{2}$ and $T_{\mathrm{c}, \mathrm{CO}_{2}}$ to ensure the safety and efficacy of ventilation.

The mode of ventilation was set to spontaneous/ timed on the VPAP II ST ${ }^{\mathrm{TM}}$ device and to timed (T) on the BiPAP ST ${ }^{\mathrm{TM}}$, the IPAPmax and \%IPAP was set to match the spontaneous respiratory effort of the patient. The respiratory rate of the device was set at the patients spontaneous awake respiratory rate on BiPAP and one breath per minute below this on VPAP. In both patients who used BiPAP the timed mode was used because of the presence of prolonged inspiratory times and ineffective ventilation in the spontaneous/timed mode. The spontaneous/timed mode, unlike the timed mode, allows the patient to trigger each breath from the ventilatory support device, and machine triggered breaths only occur in the presence of apnoea or a slowing of the patients respiratory rate below the mandatory rate set by the physician or therapist. Machine pressures were titrated with the goal of preventing apnoeic desaturation and preventing the fluctuations in $T_{\mathrm{c}}, \mathrm{CO}_{2}$, which occur at sleep onset associated with CSR. The EPAP pressure was adjusted to abolish snoring and eliminate partial upper airway obstruction and thus residual obstructive events. The IPAP pressure was used to provide either tidal volume augmentation or controlled ventilation in an attempt to abolish central apnoeas and hypnoeas (fig. 1). The IPAP pressure was not increased in the presence of spontaneous hyperventilation, that is, when the $T_{\mathrm{c}}, \mathrm{CO}_{2}$ was below the awake baseline level, in order to avoid causing glottic closure. Once acclimatized to the device, a repeat full sleep study on NPPV was performed to ensure the adequacy of ventilation and gauge the effect of treatment on both CSR and sleep quality.

\section{Statistical analysis}

All values are shown as mean \pm SD unless otherwise stated. The effect of treatment on AHI, sleep fragmentation and sleep architecture was tested using paired t-tests. A p-value of $<0.05$ was considered significant.

\section{Results}

\section{Patients}

Nine subjects with CHF and CSR during sleep were studied. The patient's baseline clinical characteristics including anthropometric data, New York Heart a)
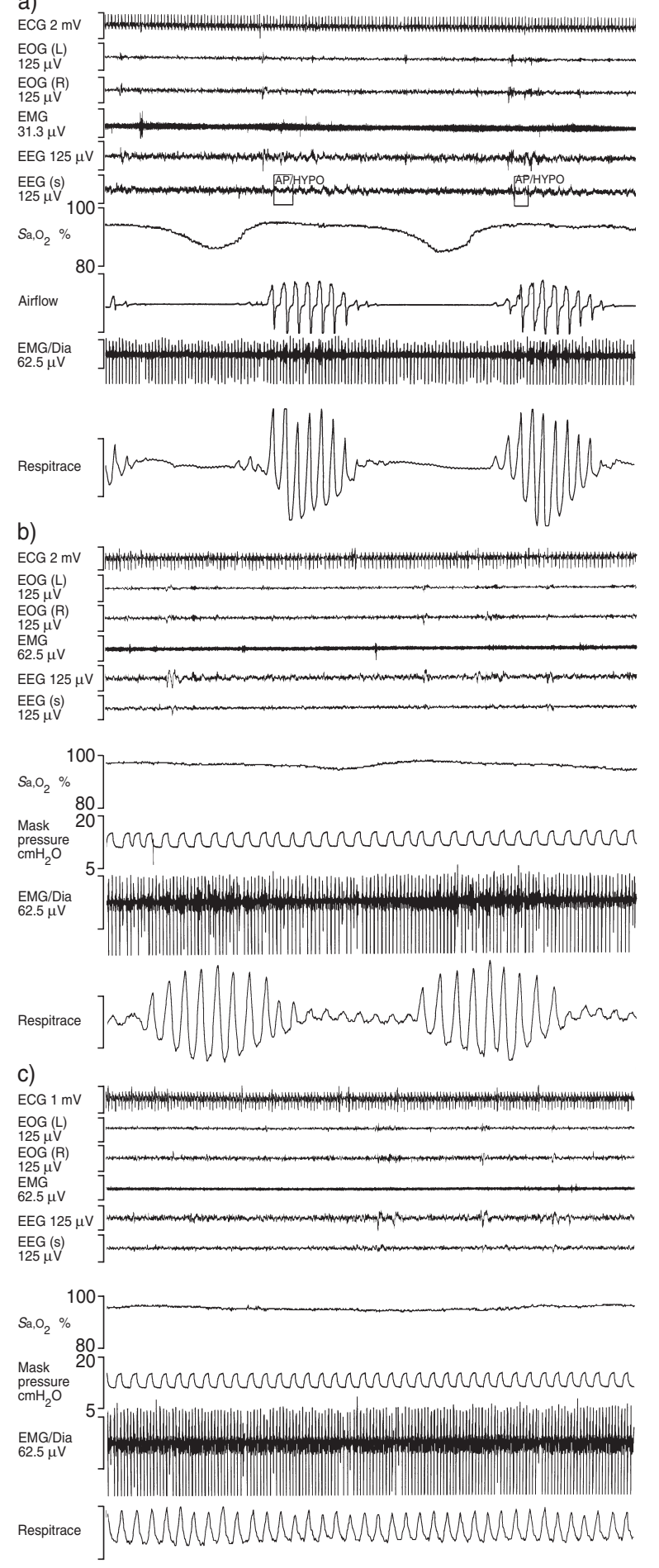

Fig. 1. - Illustrative epochs (2 min) during nonrapid eye movement sleep from a patient with congestive heart failure during: a) repetitive Cheyne-Stokes respiration with arousals on diagnostic night; b) sleep onset undergoing noninvasive pressure preset ventilation (NPPV) showing the conversion of apnoeic events to hypopnoeas. Note the maintained respitrace signal synchronous with mask pressure during periods of absent diaphragm electromyography (EMG), a dampening of oscillations in arterial oxyhaemoglobin saturation $\left(\mathrm{Sa}_{\mathrm{a}} \mathrm{O}_{2}\right)$ results and c) consolidated sleep, absence of diaphragm EMG, stable respiration and $S_{\mathrm{a}, \mathrm{O}_{2}}$ during treatment with NPPV. ECG: electrocardiogram; EOG: two channels of electro-oculogram; (EOG: LOC/ ROC); EMG: submental electromyogram; EEG: electroencephalogram (C4/A1 or C3/A2); EEG (s): electroencephalogram (01/A2 or 02/A1); airflow: nasal airflow. 
Association functional class (NYHA), LVEF, body mass index (BMI) and arterial blood gases are shown in table 1 . The mean age of the patients was $65 \pm$ 11 yrs (range 47-79 yrs), they were mostly nonobese with a mean BMI of $27.3 \pm 3.8 \mathrm{~kg} \cdot \mathrm{m}^{2}$, the highest BMI being $32.8 \mathrm{~kg} \cdot \mathrm{m}^{2}$. Left ventricular function was predominantly at least moderately impaired with an LVEF of $25 \pm 8 \%$ (range $13-40 \%$ ). The cardiac medications, which the patients were using, included: converting enzyme inhibitor $(n=7)$, diuretic $(n=8)$, digoxin $(\mathrm{n}=5)$, amiodarone $(\mathrm{n}=2)$, long acting nitrates $(n=4)$, calcium antagonist $(n=1)$. No patient was taking any hypnotic or antidepressant medication. The group as a whole exhibited carbon dioxide tension in arterial blood $\left(\mathrm{Pa}, \mathrm{CO}_{2}\right)$ values at the lower end of the normal range with a mean value of $5.0 \pm 0.6 \mathrm{kPa}$ (range $3.9-5.6 \mathrm{kPa}$ ).

Patients were referred from a variety of sources. Eight patients had previously had sleep studies and trialed nCPAP but had been judged a treatment failure either due to poor compliance or inadequate therapeutic response. At the time of the study, eight of the nine patients had been prescribed some form of therapy for CSR during sleep, including: a volume preset ventilator $(n=5)$, nasal oxygen $(n=2)$, and nCPAP $(n=1)$. Three of the patients using volume preset ventilation and the patient using nCPAP had become noncompliant prior to the study. Prior to treatment, all subjects had symptoms of sleep apnoea syndrome with either a history of excessive daytime somnolence and/or witnessed apnoeas.

\section{Sleep studies}

The Dx demonstrated that all patients had significant CSR with a mean AHI of $49 \pm 10 \cdot \mathrm{h}^{-1}$ and a minimum $\mathrm{Sa}_{\mathrm{O}} \mathrm{O}_{2} 77 \pm 7 \%$. Respiratory events were almost exclusively central in nature with a CheyneStokes pattern. Seven patients demonstrated some degree of partial upper airway obstruction which was evidenced by either snoring $(\mathrm{n}=2)$ and partial obstruction $(\mathrm{n}=7)$, identified by airflow flattening during the period of hyperpnoea following central
Table 2. - Sleep study data

\begin{tabular}{lccc}
\hline & $\begin{array}{c}\text { Diagnostic } \\
\text { study }\end{array}$ & NPPV & p-value \\
\hline Total sleep time, min & $271 \pm 79$ & $283 \pm 53$ & NS \\
Minimum $\mathrm{Sa}_{\mathrm{a}, \mathrm{O}_{2} \%} \%$ & $72 \pm 7$ & $89 \pm 2$ & 0.01 \\
Minimum average $\mathrm{Sa}_{\mathrm{a}, \mathrm{O}_{2}} \%$ & $90 \pm 2$ & $94 \pm 1$ & 0.001 \\
Sleep efficiency \% & $62 \pm 16$ & $68 \pm 8$ & $\mathrm{NS}$ \\
Stage 1/2 \%TST & $79 \pm 7$ & $72 \pm 10$ & 0.057 \\
Slow-wave sleep \%TST & $8 \pm 6$ & $12 \pm 9$ & $\mathrm{NS}$ \\
REM \%TST & $13 \pm 7$ & $16 \pm 6$ & $\mathrm{NS}$ \\
Respiratory disturbance & $49 \pm 10$ & $6 \pm 5$ & 0.001 \\
$\quad$ index events $\cdot \mathrm{h}^{-1}$ & & & \\
Arousal index arousals $\cdot \mathrm{h}^{-1}$ & $42 \pm 6$ & $17 \pm 7$ & 0.001 \\
Heart rate beats per minute & $73.9 \pm 9.6$ & $69.3 \pm 13.1$ & $\mathrm{NS}$ \\
\hline
\end{tabular}

Data are presented as mean $\pm \mathrm{SD}$. NPPV: noninvasive pressure preset ventilation; TST: total sleep time; $S_{\mathrm{a}, \mathrm{O}_{2}}$ : arterial oxyhaemoglobin saturation. \$: mean of the 1st 30 mins nonrapid eye movement. p-Values $>0.1$ are expressed as not significant (NS).

apnoea. One patient demonstrated obstructive apnoeas during REM.

The sleep study data are summarized in table 2 . The use of NPPV during sleep reduced CSR in all patients, with a decrease in the AHI from $49 \pm 10 \cdot \mathrm{h}^{-1}$ to $5 \pm 6 \cdot h^{-1} \quad(p<0.001)$ (fig. 2$)$. In the subgroup (seven of nine) who used the spontaneous/timed mode, the AHI fell from $48 \pm 11 \cdot h^{-1}$ to $5 \pm 5 \cdot h^{-1}(p<0.001)$. Residual respiratory events predominantly occurred at sleep onset. $T \mathrm{c}, \mathrm{CO}_{2}$ whilst on NPPV did not change from spontaneously breathing awake levels (5.38 \pm $0.89 \mathrm{kPa}$ awake versus $5.48 \pm 1.00 \mathrm{kPa}$ during NPPV (NS)) (table 3). There was no evidence of ventilator induced hyperventilation and uncontrolled hypocapnia whilst using NPPV.

Pressure preset ventilation markedly reduced the total number of arousals from $42 \pm 6 \cdot h^{-1}$ to $17 \pm 7 \cdot h^{-1}$ $(\mathrm{p}<0.001)$ (fig. 3). The duration and efficiency of sleep were unaffected by the introduction of NPPV. Sleep architecture also remained unchanged on NPPV, although a trend toward more consolidated sleep was present.

Table 1.- Patient characteristics

\begin{tabular}{|c|c|c|c|c|c|c|c|c|c|c|}
\hline & \multirow[t]{2}{*}{ Sex } & \multirow{2}{*}{$\begin{array}{l}\text { Age } \\
\text { yrs }\end{array}$} & \multirow[t]{2}{*}{ Etiology } & \multirow{2}{*}{$\underset{\%}{\mathrm{LVEF}}$} & \multirow[t]{2}{*}{ NYHA } & \multirow{2}{*}{$\underset{\mathrm{kg} \cdot \mathrm{m}^{-2}}{\mathrm{BMI}}$} & \multicolumn{4}{|c|}{ Arterial blood gases } \\
\hline & & & & & & & $\overline{\mathrm{pH}}$ & $\begin{array}{l}\mathrm{Pa}_{\mathrm{a}, \mathrm{O}_{2}} \\
(\mathrm{kPa})\end{array}$ & $\begin{array}{l}\mathrm{Pa}_{\mathrm{a}, \mathrm{CO}_{2}} \\
(\mathrm{kPa})\end{array}$ & $\begin{array}{l}\mathrm{Sa}_{\mathrm{a}, \mathrm{O}_{2}} \\
(\%)\end{array}$ \\
\hline & $\mathrm{M}$ & 54 & CAD & 16 & 3 & 30.0 & 7.42 & 11.7 & 4.7 & 98.0 \\
\hline & $\mathrm{M}$ & 77 & CAD & 40 & 2 & 25.6 & 7.43 & 12.9 & 5.1 & 98.0 \\
\hline & $\mathrm{M}$ & 79 & CAD & 22 & 3 & 23.1 & 7.39 & 11.7 & 5.1 & 97.0 \\
\hline & $\mathrm{M}$ & 67 & CAD & 33 & 3 & 28.5 & 7.41 & 12.1 & 5.6 & 97.0 \\
\hline & $\mathrm{F}$ & 58 & CAD & 30 & 4 & 26.3 & 7.38 & 12.1 & 3.9 & 97.0 \\
\hline & $\mathrm{M}$ & 73 & DCM & 13 & 4 & 20.5 & 7.41 & 9.2 & 5.3 & 94.0 \\
\hline & $\mathrm{M}$ & 66 & CAD & 24 & 3 & 30.2 & 7.43 & 10.5 & 5.3 & 96.0 \\
\hline & M & 69 & CAD & 27 & 1 & 28.9 & 7.38 & 12.4 & 5.6 & 97.0 \\
\hline & $\mathrm{M}$ & 47 & DCM & 22 & 3 & 32.8 & 7.31 & 14.5 & 4.7 & 98.0 \\
\hline Mean \pm SD & & $65 \pm 11$ & & $25 \pm 8$ & 2.9 & $27.3 \pm 3.8$ & $7.39 \pm 0.04$ & $11.9 \pm 1.5$ & $5.0 \pm 0.6$ & $97 \pm 1$ \\
\hline
\end{tabular}

M: male; F: female; NYHA: New York Heart Association Functional Class; CAD: coronary artery disease; DCM: dilated cardiomyopathy; BMI: body mass index; LVEF: left ventricular ejection fraction; $P \mathrm{a}_{2} \mathrm{O}_{2}$ : oxygen tension in arterial blood; $\mathrm{Pa}_{\mathrm{a}} \mathrm{CO}_{2}$ : carbon dioxide tension in arterial blood; $\mathrm{Sa}, \mathrm{O}_{2}$ : arterial oxyhaemoglobin saturation. 


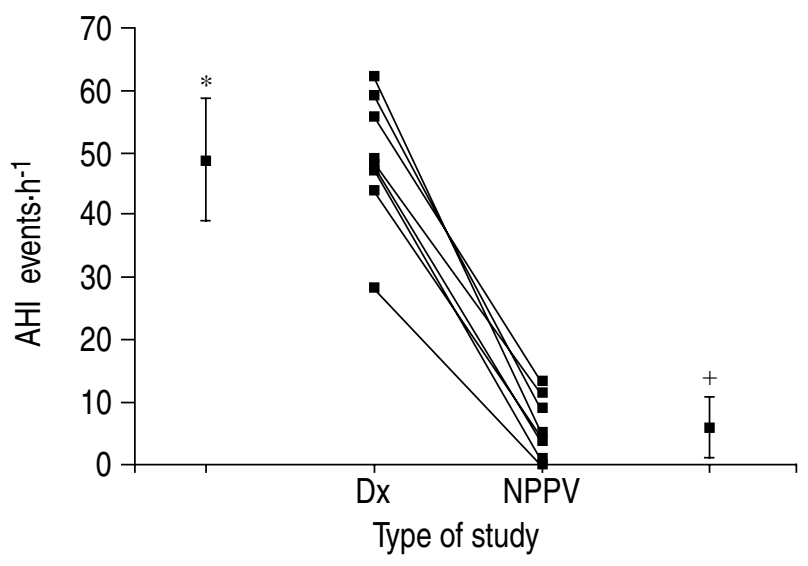

Fig. 2. - Change in apnoea/hypopnoea index (AHI). Dx: diagnostic study whilst breathing room air; NPPV: noninvasive pressure preset ventilation. $\mathrm{p}<0.001$. $^{*}$ : mean $\pm \mathrm{SD}$ for $\mathrm{Dx} ;{ }^{+}:$mean \pm SD for NPPV.

\section{Acclimatization}

Patients adapted rapidly to NPPV, the median length of hospital stay was 4 days (range $1-8$ days). All patients who had previously used volume preset ventilation or nCPAP reported improved comfort when using NPPV. The BiPAP ${ }^{\mathrm{TM}}$ device was used in two patients, and the VPAP II ST ${ }^{\mathrm{TM}}$ in the remaining seven patients. Individual patient settings are shown in table 4.

\section{Discussion}

In this study it has been shown that NPPV can markedly reduce CSR and the central sleep apnoea which occurs as part of it in patients with CHF. NPPV substantially reduced the AHI in all patients. Notably, NPPV also worked effectively when the devices were in the spontaneous/timed mode. This improvement in breathing during sleep resulted in a marked reduction in the number of arousals. This marked reduction in sleep fragmentation was associated with a preservation

Table 3. - Transcutaneous carbon dioxide $\left(T_{\mathrm{c}}, \mathrm{CO}_{2}\right)$ during noninvasive pressure preset ventilation

\begin{tabular}{llll}
\hline Patient & $\begin{array}{c}T_{\mathrm{c}, \mathrm{CO}_{2}} \\
\text { awake* } \mathrm{kPa}\end{array}$ & $\begin{array}{c}T_{\mathrm{c}, \mathrm{CO}_{2}} \\
\text { asleep }\end{array}$ & $\begin{array}{c}T_{\mathrm{c}, \mathrm{CO}_{2}} \\
\text { difference }\end{array}$ \\
\hline 1 & 6.00 & 6.75 & 0.75 \\
2 & 4.80 & 4.73 & -0.07 \\
3 & 4.13 & 3.80 & -0.33 \\
4 & 5.60 & 6.15 & 0.55 \\
5 & 4.80 & 4.99 & 0.19 \\
$6^{\bullet}$ & 5.07 & 5.21 & 0.15 \\
$7^{\Phi+}$ & 7.20 & 7.01 & -0.19 \\
$8^{+}$ & 5.07 & 5.29 & 0.23 \\
$9^{+}$ & 5.73 & 5.41 & -0.32 \\
Mean $\pm \mathrm{SD}$ & $5.38 \pm 0.89$ & $5.48 \pm 1.00$ & $0.11 \pm 0.37$ \\
\hline
\end{tabular}

*: awake and breathing spontaneously; ${ }^{*}$ : mean of the first 30 mins of nonrapid eye movement; ": patients used bilevel positive airway pressure; ${ }^{+}: T_{\mathrm{c}, \mathrm{CO}_{2}}$ measured at subsequent study.

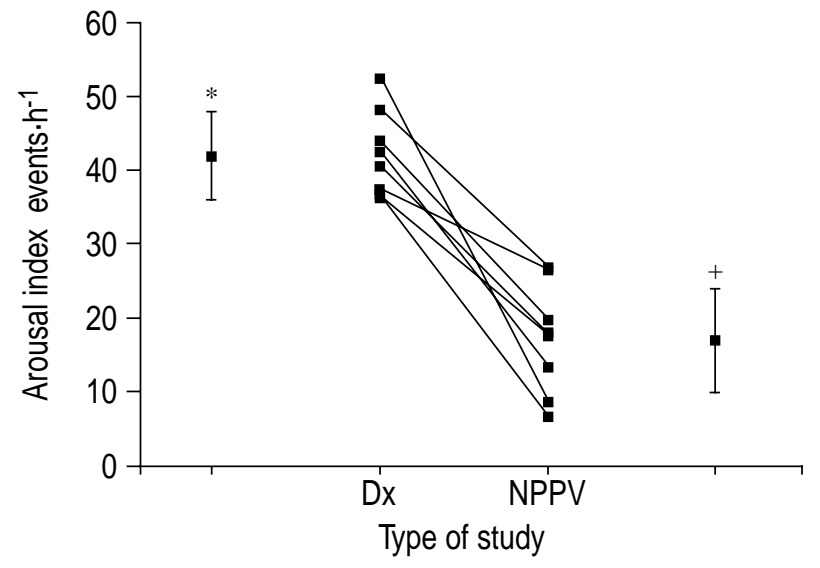

Fig. 3. - Change in arousal index. Dx: diagnostic study whilst breathing room air; NPPV: noninvasive pressure preset ventilation, $\mathrm{p}<0.001$. *: mean $\pm \mathrm{SD}$ for $\mathrm{Dx} ;{ }^{+}$: mean $\pm \mathrm{SD}$ for NPPV.

of the total duration of sleep stages indicating consolidation and improvement of sleep. However, there was no significant increase in overall SWS and REM sleep.

CSR is a crescendo-decrescendo oscillation of tidal volume, which occurs predominantly in light sleep in patients with CHF. CSR is observed in association with hypocapnia, a low mean sleep $T_{\mathrm{c},} \mathrm{CO}_{2}[5,6]$ and a failure of $T \mathrm{c}, \mathrm{CO}_{2}$ to rise at sleep onset as is seen in normal subjects and heart failure patients without CSR [25]. The particular mechanisms, which lead to CSR in CHF, remain to be fully explained, but an augmented ventilatory drive and ventilatory response to carbon dioxide appears to be pivotal $[3,26]$.

nCPAP has been shown to reduce CSR following a 1 month acclimatization. Improvement in cardiac performance was also documented following nCPAP therapy [27]. In a number of randomized, controlled trials from one centre, nCPAP has also been shown to improve both sleep quality and daytime myocardial function [14-16]. Mechanisms of improvement were thought to be increased intrathoracic pressure and a reduction in the number of apnoeas and arousals from sleep. Other groups, however, have reported no change or an increase in CSR during the acute administration of nCPAP and found the treatment to be poorly tolerated $[17-19]$. The reasons for the disparity between centres may be related to the length of nCPAP acclimatization, the level of nCPAP used and the severity of the CSR. The present study centre has extensive experience with the initiation of nCPAP therapy, yet the patients with $\mathrm{CHF}$ frequently experience a lack of symptomatic response and are poorly compliant with nCPAP long-term, despite hospital acclimatization and intensive home support. Oxygen therapy has been shown to be effective in partly reducing CSR [11, 28] and sympathetic tone [29], and increasing exercise tolerance [28], although no improvements in symptoms or cognitive function were found after 4 weeks in a recent trial [29]. A recent report documented the heightened effectiveness of the combined use of oxygen and carbon dioxide in reducing CSR, although this treatment resulted in a 
Table 4.- Ventilator settings used to control Cheyne-Stokes respiration

\begin{tabular}{|c|c|c|c|c|c|c|}
\hline Device & Mode & EPAP $\mathrm{cmH}_{2} \mathrm{O}$ & IPAP $\mathrm{cmH}_{2} \mathrm{O}$ & Rate bpm & IPAP max & $\%$ IPAP \\
\hline \multirow{7}{*}{ VPAP II } & $\mathrm{S} / \mathrm{T}$ & 11 & 17 & 18 & 1.65 & \\
\hline & $\mathrm{S} / \mathrm{T}$ & 5 & 14.5 & 14 & 1.50 & \\
\hline & $\mathrm{S} / \mathrm{T}$ & 5 & 15 & 14 & 1.45 & \\
\hline & $\mathrm{S} / \mathrm{T}$ & 8 & 16 & 14 & 1.65 & \\
\hline & $\mathrm{S} / \mathrm{T}$ & 7 & 14 & 16 & 1.50 & \\
\hline & $\mathrm{S} / \mathrm{T}$ & 10 & 17 & 14 & 1.65 & \\
\hline & $\mathrm{S} / \mathrm{T}$ & 9 & 16 & 13 & 1.65 & \\
\hline \multirow[t]{2}{*}{ BiPAP } & $\mathrm{T}$ & 10 & 20 & 17 & & 40 \\
\hline & $\mathrm{T}$ & 4 & 14 & 16 & & 30 \\
\hline Mean $\pm S D$ & & $7.9 \pm 2.5$ & $15.6 \pm 1.9$ & $14.7 \pm 1.7$ & $1.58 \pm 0.09$ & $35 \pm 7$ \\
\hline
\end{tabular}

VPAP: variable positive airway pressure; BiPAP: bilevel positive airway pressure; S/T: spontaneous/timed; EPAP: expiratory positive airway pressure; IPAP: inspiratory positive airway pressure; bpm: breaths per min.

potentially adverse increase in sympathetic activation [30]. JAVAHERI et al. [12] proposed the use of theophylline following a randomized trial in which central apnoeas were reduced in the treatment group. Unfortunately, the results of this study were confounded by the simultaneous administration of oxygen during the treatment period. Thus, at present there is no universally accepted treatment for CSR.

Noninvasive ventilation is widely used in the treatment of patients with respiratory failure. Patients treated with this modality included those with chest wall deformities, neuromuscular disease, control of breathing abnormalities and lung disease [31]. Noninvasive ventilation is used in these conditions in an attempt to abolish episodes of nocturnal hypoventilation and therefore normalize gas exchange. The authors have previously reported their success in the use of noninvasive ventilation via a volume preset device in patients with heart failure and severe CSR [20]. Despite its effectiveness in reducing CSR (AHI: $54 \pm 14$ to $5 \pm 6 \cdot h^{-1}$ ), a number of patients failed to tolerate the device in domiciliary setting, partly due to the mandatory nature of the set respiratory rate and the insensitivity of the inspiratory triggering. Pressure preset devices are becoming more widely used in the treatment of respiratory failure due to their effectiveness, ease of operation and increased comfort [21, 22].

In the present study, pressure preset ventilation substantially reduced AHI from $49 \pm 10$ to $6 \pm 5 \cdot \mathrm{h}^{-1}$. Although it is obvious that if a patient can tolerate being ventilated and remain asleep, if the arterial carbon dioxide is held below the patients own apnoea threshold [7], then the ventilator will override the underlying breathing rhythm disturbance. It is believed that NPPV attenuates fluctuations in oxygen tension in arterial blood $\left(\mathrm{Pa}, \mathrm{O}_{2}\right)$ and $\mathrm{Pa}, \mathrm{CO}_{2}$ by supporting ventilation during the apnoea portion of the Cheyne-Stokes cycle, thereby preventing oscillations of $\mathrm{Pa}_{1} \mathrm{CO}_{2}$ above and below the apnoea threshold. A major concern with the use of patient triggered mechanical ventilation in a subject who is already hyperventilating, is that it could cause further uncontrolled hyperventilation and a worsening of the respiratory abnormality. On the contrary, as a group $T_{\mathrm{c}}, \mathrm{CO}_{2}$ rose on NPPV during sleep $(5.38 \pm 0.89 \mathrm{kPa}$ awake versus $5.48 \pm 1.00 \mathrm{kPa}$, (Ns)), and fluctuations in blood gases and CSR were also greatly reduced.
However, $T_{\mathrm{c}, \mathrm{CO}_{2}}$ changes whilst using NPPV were variable throughout the group suggesting that the mechanism of CSR reduction may not be uniform. The majority of the patients showed small fluctuations in $T \mathrm{c}, \mathrm{CO}_{2}$ during NREM compared with awake levels, and no apparent spontaneous breathing effort (absence of diaphragm EMG) during ventilation presumably because the arterial carbon dioxide was below their apnoea threshold [7]. Conversely, $T_{\mathrm{c},} \mathrm{CO}_{2}$ rose by $>0.5 \mathrm{kPa}$ in two patients who used the spontaneous/timed mode, these patients, however, also demonstrated a complete absence of diaphragm EMG suggesting that they were also breathing below their apnoea threshold. Given that other authors have noted a marked decrement in diaphragm EMG during patient triggered NPPV $[32,33]$, it would appear that further studies using more sensitive measures of effort may be needed to fully elucidate the mechanism of NPPV. During sleep onset, patients demonstrated both periods of spontaneous efforts (during hyperpnoea) and absences of effort (central apnoea) whilst using NPPV. During these absences in spontaneous respiratory effort, NPPV controlled the minute ventilation, thus attenuating and dampening changes in $S \mathrm{a}, \mathrm{O}_{2}$ and $T \mathrm{c}, \mathrm{CO}_{2}$ (fig. $1 \mathrm{~b}$ ). A similar mechanism was proposed by CHERNIACK et al. [34] for the reversal of induced CSR in cats during constant artificial respiration. In contrast, nCPAP is believed to decrease CSR by increasing the arterial carbon dioxide, thereby reducing the unstable respiratory control induced by hypocapnia [27].

Residual respiratory events on NPPV appeared to be related to both upper airway obstruction and also to the failure of this device to completely control the level of ventilation during the apnoea portion of the Cheyne-Stokes cycle. These residual events were predominantly seen at sleep onset or following movement arousals, and were rapidly dampened by ventilation. The mean EPAP pressure of $7.9 \pm$ $2.5 \mathrm{cmH}_{2} \mathrm{O}$ was high, reflecting the presence of residual upper airway obstruction in some patients. These obstructive episodes are not surprising, and a number of authors have commented on the likely role of upper airway closure in the pathogenesis of central sleep apnoea $[35,36]$. The authors observed some evidence of airway occlusive narrowing in seven of the nine patients and a number also reported a history 
consistent with occlusive apnoea which had preceded CHF. Complete pharyngeal occlusion during central apnoea has also been directly visualized using fibreoptic nasopharyngoscopy [37]. The upper airway occlusion, which was witnessed at sleep onset, may be either due to spontaneous collapse or may be precipitated by NPPV. The presence of upper airway narrowing and occlusion due to glottic closure has been documented in normal subjects when hyperventilated noninvasively whilst asleep [38, 39]. This is unlikely to be the mechanism in the present patients as $T \mathrm{c}, \mathrm{CO}_{2}$ was monitored and hyperventilation was minimized. The potential for hypocapnia to cause reflex glottic closure is a major reason why achieving effective control of CSR with a pressure preset device that does not induce hyperventilation is theoretically more desirable. The investigators were also careful not to induce excess hyperventilation on NPPV which may have other adverse consequences such as ventricular arrhythmias in $\mathrm{CHF}$ [40].

Whilst using NPPV, there was marked reduction in the overall arousal index from $42 \pm 6$ to $17 \pm 7 \cdot \mathrm{h}^{-1}$. The number of arousals observed on NPPV was comparable to that seen in normal subjects in the study laboratory $\left(20 \cdot \mathrm{h}^{-1}\right)$ [41] and by others $\left(21 \cdot \mathrm{h}^{-1}\right)$ [42]. The use of NPPV resulted in a trend toward a reduction in light sleep and, therefore, a consolidation of sleep structure. A previous study by the authors with volume preset ventilation demonstrated a reduction in Stage 1 and 2 sleep and an increase in SWS. This may reflect a more effective control of apnoea with fully controlled ventilation. Despite its effectiveness in reducing CSR and sleep fragmentation, statistically significant changes in the duration of sleep stages were not seen in the present study. This may reflect the small number of patients included and the underlying abnormalities in sleep architecture seen in heart failure patients in the absence of CSR [5, 15]. Heart rate during the first 30 min of NREM was not statistically altered by NPPV, although five of the nine patients experienced a drop in heart rate of $>9 \%$ whilst using NPPV. Further studies are necessary to elucidate the acute and chronic haemodynamic effects of NPPV in CHF.

The authors did not use a formal sleep laboratory acclimatization or a control group as part of the present investigation. Eight of the nine subjects had undergone previous sleep studies prior to enrolment and were, therefore, accustomed to the laboratory environment. These subjects had also undergone an in-laboratory nCPAP trial and seven had previously been participants in a study looking at the effects of volume preset ventilation on sleep [20]. This previous study demonstrated the reproducibility of repeat sleep studies in heart failure patients with CSR. Numerous controlled trials have shown the reproducibility of sleep study data in those patients randomized to the control and placebo [12, 14, 15], other authors have noted the remarkable consistency of polysomnographic findings in these patients [43].

In this study, the acute effects of NPPV in patients with CSR were examined. The authors did not attempt to assess the effects of long-term therapy on mortality, cardiac function and quality of life. Clearly, further studies are needed to evaluate the effects of this therapy on cardiac function and prognosis and compare noninvasive ventilation to currently proposed therapies such as oxygen and nCPAP.

In summary, the study has shown that CheyneStokes respiration in sleep can be effectively treated with the use of noninvasive pressure preset ventilation. This improvement in sleep breathing results in reduced arousal and improved sleep quality in these patients. Noninvasive pressure preset ventilation should be considered a potential therapy for Cheyne-Stokes respiration in heart failure in those patients who do not respond or fail to tolerate nasal continuous positive airway pressure therapy.

Acknowledgements. The authors thank the nursing and medical staff of the Centre for Respiratory Failure and Sleep Disorders for their help during this study.

\section{References}

1. Hanly PJ, Millar TW, Steljes DG, Baert R, Frais MA, Kryger MH. Respiration and abnormal sleep in patients with congestive heart failure. Chest 1989; 96: $480-488$.

2. Javaheri S, Parker TJ, Liming JD, et al. Sleep apnea in 81 ambulatory male patients with stable heart failure. Types and their prevalences, consequences, and presentations. Circulation 1998; 97: 2154-2159.

3. Wilcox I, Grunstein RR, Collins FL, Berthon Jones M, Kelly DT, Sullivan CE. The role of central chemosensitivity in central apnea of heart failure. Sleep 1993; 16: Suppl. 8, S37-S38.

4. Wilcox I, McNamara SG, Dodd MJ, Sullivan CE. Ventilatory control in patients with sleep apnoea and left ventricular dysfunction: comparison of obstructive and central sleep apnoea. Eur Respir J 1998; 11: 7-13.

5. Hanly P, Zuberi N, Gray R. Pathogenesis of CheyneStokes respiration in patients with congestive heart failure. Relationship to arterial $\mathrm{PCO}_{2}$. Chest 1993; 104: $1079-1084$.

6. Naughton M, Benard D, Tam A, Rutherford R, Bradley TD. Role of hyperventilation in the pathogenesis of central sleep apneas in patients with congestive heart failure. Am Rev Respir Dis 1993; 148: $330-338$.

7. Dempsey JA, Skatrud JB. A sleep-induced apneic threshold and its consequences. Am Rev Respir Dis 1986; 133: $1163-1170$.

8. Bradley TD, Floras JS. Pathophysiologic and therapeutic implications of sleep apnea in congestive heart failure. J Card Fail 1996; 2: 223-240.

9. Hanly PJ, Zuberi Khokhar NS. Increased mortality associated with Cheyne-Stokes respiration in patients with congestive heart failure. Am J Respir Crit Care Med 1996; 153: 272-276.

10. Lanfranchi PA, Braghiroli A, Bosimini E, et al. Prognostic value of nocturnal Cheyne-Stokes Respiration in Chronic Heart Failure. Circulation 1999; 99: $1435-1440$.

11. Hanly PJ, Millar TW, Steljes DG, Baert R, Frais MA, Kryger $\mathrm{MH}$. The effect of oxygen on respiration and 
sleep in patients with congestive heart failure. Ann Intern Med 1989; 111: 777-782.

12. Javaheri S, Parker TJ, Wexler L, Liming JD, Lindower P, Roselle GA. Effect of theophylline on sleep-disordered breathing in heart failure. $N \mathrm{Engl}$ J Med 1996; 335: 562-567.

13. Takasaki Y, Orr D, Popkin J, Rutherford R, Liu P, Bradley TD. Effect of nasal continuous positive airway pressure on sleep apnea in congestive heart failure. Am Rev Respir Dis 1989; 140: $1578-1584$.

14. Naughton MT, Liu PP, Benard DC, Goldstein RS, Bradley TD. Treatment of congestive heart failure and Cheyne-Stokes respiration during sleep by continuous positive airway pressure. Am J Respir Crit Care Med 1995; 151: $92-97$.

15. Naughton MT, Benard DC, Liu PP, Rutherford R, Rankin F, Bradley TD. Effects of nasal CPAP on sympathetic activity in patients with heart failure and central sleep apnea. Am J Respir Crit Care Med 1995; 152: $473-479$.

16. Granton JT, Naughton MT, Benard DC, Liu PP, Goldstein RS, Bradley TD. CPAP improves inspiratory muscle strength in patients with heart failure and central sleep apnea. Am J Respir Crit Care Med 1996; 153: $277-282$.

17. Davies RJ, Harrington KJ, Ormerod OJ, Stradling JR. Nasal continuous positive airway pressure in chronic heart failure with sleep-disordered breathing. Am Rev Respir Dis 1993; 147: 630-634.

18. Buckle P, Millar T, Kryger M. The effect of shortterm nasal CPAP on Cheyne-Stokes respiration in congestive heart failure. Chest 1992; 102: 31-35.

19. Guilleminault C, Clerk A, Labanowski M, Simmons J, Stoohs R. Cardiac failure and benzodiazepines. Sleep 1993; 16: $524-528$.

20. Willson GN, Wilcox I, Piper AJ, Flynn WE, Grunstein RR, Sullivan CE. Treatment of central sleep apnoea in congestive heart failure with nasal ventilation. Thorax 1998; 53: Suppl. 3, S41-46.

21. Schonhofer B, Sonneborn M, Haidl P, Bohrer HDK. Comparison of two different modes for noninvasive mechanical ventilation in chronic respiratory failure: volume versus pressure controlled device. Eur Respir J 1997; 10: $184-191$.

22. Girault C, Richard JC, Chevron V, Tamion F, Pasquis $\mathrm{P}$, Leroy J, Bonmarchand G. Comparative physiologic effects of noninvasive assist-control and pressure support ventilation in acute hypercapnic respiratory failure. Chest 1997; 111: 1639-1648.

23. Rechtschaffen A, Kales A. A manual of standardized terminology, techniques and scoring system for sleep stages of human subjects. Washington DC, National Institutes of Health, 1968.

24. Bonnet $\mathrm{MH}$, Carley D, Carskadon M, et al. EEG arousals: scoring rules and examples. A preliminary report from the Sleep Disorders Atlas Task Force of the American Sleep Disorders Association. Sleep 1992; 15: $174-184$.

25. Tkacova R, Hall MJ, Liu PP, Fitzgerald FS, Bradley TD. Left ventricular volume in patients with heart failure and Cheyne-Stokes respiration during sleep. Am J Respir Crit Care Med 1997; 156: 1549-1555.

26. Andreas S, von Breska B, Kopp E, Figulla HR, Kreuzer H. Periodic respiration in patients with heart failure. Clin Investig 1993; 71: 281 - 285.
27. Naughton MT, Benard DC, Rutherford R, Bradley TD. Effect of continuous positive airway pressure on central sleep apnea and nocturnal $P_{C O}$ in heart failure. Am J Respir Crit Care Med 1994; 150: 1598 1604.

28. Andreas S, Clemens C, Sandholzer H, Figulla HR, Kreuzer H. Improvement of exercise capacity with treatment of Cheyne-Stokes respiration in patients with congestive heart failure. J Am Coll Cardiol 1996; 27: $1486-1490$.

29. Staniforth AD, Kinnear WJ, Starling R, Hetmanski DJ, Cowley AJ. Effect of oxygen on sleep quality, cognitive function and sympathetic activity in patients with chronic heart failure and Cheyne-Stokes respiration. Eur Heart J 1998; 19: 922-928.

30. Andreas S, Weidel K, Hagenah G, Heindl S. Treatment of Cheyne-Stokes respiration with nasal oxygen and carbon dioxide. Eur Respir J 1998; 12: 414-419.

31. Piper AJ, Willson GN. Nocturnal nasal ventilatory support in the management of daytime hypercapnic respiratory failure. Aust J Physiother 1996; 42: 17-29.

32. Brochard L, Isabey $\mathrm{D}$, Piquet $\mathrm{J}$, et al. Reversal of acute exacerbations of chronic obstructive lung disease by inspiratory assistance with a face mask. $N$ Engl J Med 1990; 323: 1523-1530.

33. Appendini L, Patessio A, Zanaboni S, et al. Physiologic effects of positive end-expiratory pressure and mask pressure support during exacerbations of chronic obstructive pulmonary disease. Am J Respir Crit Care Med 1994; 149: 1069-1076.

34. Cherniack NS, von Euler C, Homma I, Kao FF. Experimentally induced Cheyne-Stokes breathing. Respir Physiol 1979; 37: 185-200.

35. Issa FG, Sullivan CE. Reversal of central sleep apnea using nasal CPAP. Chest 1986; 90: 165-171.

36. Alex CG, Onal E, Lopata M. Upper airway occlusion during sleep in patients with Cheyne-Stokes respiration. Am Rev Respir Dis 1986; 133: $42-45$.

37. Badr MS, Toiber F, Skatrud JB, Dempsey J. Pharyngeal narrowing/occlusion during central sleep apnea. J Appl Physiol 1995; 78: $1806-1815$.

38. Parreira VF, Jounieaux V, Aubert G, Dury M, Delguste PE, Rodenstein DO. Nasal two-level positive-pressure ventilation in normal subjects. Effects of the glottis and ventilation. Am J Respir Crit Care Med 1996; 153: 1616-1623.

39. Jounieaux V, Aubert G, Dury M, Delguste P, Rodenstein DO. Effects of nasal positive pressure hyperventilation on the glottis in normal sleeping subjects. J Appl Physiol 1995; 79: 186-193.

40. Javaheri S, Corbett WS. Association of low $\mathrm{Pa}_{\mathrm{a}} \mathrm{CO}_{2}$ with central sleep apnea and ventricular arrhythmias in ambulatory patients with stable heart failure. Ann Intern Med 1998; 128: 204-207.

41. Lawrence S, Edwards N, Grunstein R, Berthon-Jones M. Frequency of arousals in sleep laboratory control subjects (Abstract). Australasian Sleep Association, Annual Scientific Meeting, 1995.

42. Mathur R, Douglas NJ. Frequency of EEG arousals from nocturnal sleep in normal subjects. Sleep 1995; 18: $330-333$.

43. Hanly P, Zuberi Khokhar N. Daytime sleepiness in patients with congestive heart failure and CheyneStokes respiration. Chest 1995; 107: 952-958. 